\title{
The Political Feasibility of
} Enhancing Greenhouse Gas Emissions Targets in the European Union's Mid-Century Strategy

Al Jawhara Al Quayid, Saleh Al Muhanna, Paul Mollet 


\section{About KAPSARC}

The King Abdullah Petroleum Studies and Research Center (KAPSARC) is a non-profit global institution dedicated to independent research into energy economics, policy, technology and the environment across all types of energy. KAPSARC's mandate is to advance the understanding of energy challenges and opportunities facing the world today and tomorrow, through unbiased, independent, and high-caliber research for the benefit of society. KAPSARC is located in Riyadh, Saudi Arabia.

\section{Legal Notice}

(C) Copyright 2019 King Abdullah Petroleum Studies and Research Center (KAPSARC). No portion of this document may be reproduced or utilized without the proper attribution to KAPSARC. 


\section{Key Points}

he European Union (EU) is the world's third largest carbon emitter after China and the United States, rendering its efforts to combat emissions critical to achieving the Paris Agreement target of limiting warming to well below 2-degrees Celsius $\left(2^{\circ} \mathrm{C}\right)$ above pre-industrial levels. In this study, we discuss the political feasibility of an EU-wide 80\% greenhouse gas (GHG) emissions reduction below 1990 levels by 2050, a target initially raised by the European Commission in 2011. We used the KAPSARC Toolkit for Behavioral Analysis (KTAB) to simulate the collective decision-making process among EU stakeholders regarding the EU's mid-century strategy. The paper analyzes stakeholders' mid-2018 positions on the $80 \%$ target before the EU announced its new carbon neutrality target in November 2018. Key findings from the study include:

Climate policy is of major concern to all EU member states. This includes progressive EU countries that aim to limit the effect of carbon emissions through cleaner energy sources and countries dependent on coal and fossil fuels that are looking for cost-efficient solutions and energy security.

Consensus supporting the EU-wide 80\% 2050 emissions reduction target does not appear to be politically feasible without additional concessions, based on mid-2018 data, because of member states' domestic political considerations and energy constraints. However, a 70\% emissions reduction target might be feasible.

The Visegrád Group (Poland, Hungary, the Czech Republic and Slovakia), plus Romania and Bulgaria, initially opposed the Commission's proposal. However, most of these countries ultimately saw value in joining the consensus view. Poland, however, is unlikely to accept any reduction target above $45 \%$, indicating that the Commission might need to re-think its target or offer additional incentives to Poland to inventivize its concurrence.

Climate-progressive EU member states, such as Sweden, that were expected to push for targets higher than $80 \%$ might have to accept a compromise in favor of a less ambitious target.

The United Kingdom's proposed withdrawal from the EU, commonly referred to as Brexit, is likely to have little to no effect on the outcome of the next round of EU climate negotiations. 
A rticle 4.19 of the 2015 Paris Agreement calls on signatories to formulate and communicate "long-term low greenhouse gas development strategies," widely known as the mid-century strategy (MCS). Any enhancement of the European Union's (EU's) targets in its MCS depends on a new long-term EU climate policy subject to ongoing negotiations between member states. The EU submits one nationally determined contribution (NDC) for all 28 member states, likely soon to be 27 following the proposed departure of the United Kingdom (U.K.) from the EU (Brexit). In 2011 the European Commission outlined an indicative $80 \%$ emissions reduction target in its 2050 low carbon economy roadmap compared to 1990 levels. In a move away from a targetcentered approach, the European Commission's most recent communication entitled "A Clean Planet for all - A European strategic long-term vision for a prosperous, modern, competitive and climate neutral economy" calls for carbon neutrality by 2050 but avoids any mention of targets. It instead outlines scenarios that offer policy pathways for EU member states. This paper shows that in mid-2018, EU members were unwilling to commit to higher targets, which could provide an insight into what was an unexpected shift in European Commission policy.

This paper uses the KAPSARC Toolkit for Behavioral Analysis (KTAB), a model of collective decision-making processes, to identify stakeholders' positions in mid-2018 on the expected EU-wide 2050 emissions reduction target. We used the model to assess the evolving positions and ambition levels of each EU member country, the European Commission and the European Parliament.

The KTAB simulation indicated that achieving an EU consensus around an $80 \%$ target was not politically feasible. It indicated that the positions of member states and the importance they attached to climate targets significantly impacted the outcome of notional negotiations. Results from the KTAB simulation suggested that consensus was more likely to form around a $70 \%$ emissions reduction target. While all the subject matter experts interviewed for this study were of the view that member states would likely agree on the Commission's original target, the simulation indicated that the negotiation process faced considerable hurdles.

The KTAB simulation indicated that while levels of support for the target initially varied among EU member states, the majority of EU members could ultimately reach a consensus around an emissions reduction target of $70 \%$. Most members of the Visegrád Group (Poland, Hungary, the Czech Republic and Slovakia), joined by Romania and Bulgaria, were expected to initially oppose the Commission's $80 \%$ target but would ultimately join the consensus. Poland remained committed to a much lower target, suggesting that it would seek to obstruct the pace and level of ambition of the proposal.

A unanimous vote in the European Council could be required depending on the governance pathways chosen by the Commission. If this is the case, the KTAB simulation showed that the Commission would need to offer concessions to Poland and other recalcitrants in order to obtain their support. This could be in the form of financial incentives to help member states pay for the investments required to achieve an enhanced target, lower burden sharing requirements that allow states to reduce emissions at a slower rate, or a greater focus on the use of carbon sinks to offset emissions. At the other end of the spectrum, Sweden remained committed to a $90 \%$ target. 
In order to assess the effect of Brexit, we tested a scenario in which the U.K. was removed as an actor. The resulting simulation showed minimal to no effect of the U.K.'s withdrawal on the expected outcome: a consensus among EU member states was still possible around a $70 \%$ target. The U.K.'s departure does not appear to create a major void at the negotiation table, despite its relatively progressive stance on climate policy among EU members. 
his study applies the KAPSARC Toolkit for Behavioral Analysis (KTAB), a model of collective decision-making processes (CDMPs), to assess the political feasibility of increasing European Union (EU) emissions reduction targets. It analyzes the CDMP among all current EU member states, the European Parliament and the European Commission with respect to the Paris Agreement. This analysis aims to gain insight into a possible enhancement of the EU's midcentury strategy (MCS) under the Paris Agreement and the United Nations Framework Convention on Climate Change (UNFCCC).

Much of the existing policy focus for most signatories to the Paris Agreement, which was adopted at the 21st session of the Conference of the Parties (COP 21), is on nationally determined contributions (NDCs). NDCs are non-binding commitments that outline countries' post-2020 climate action plans; they are short-term fiveyear action plans. The EU's MCS can provide an important indicator of the direction that future NDCs will take in order to meet the Paris Agreement's objective of holding the increase in the global average temperature to well below 2-degrees Celsius $\left(2^{\circ} \mathrm{C}\right)$ above pre-industrial levels and limiting the global temperature increase to $1.5^{\circ} \mathrm{C}$ above preindustrial levels.

The EU is unique within the COP process in that it comprises a number of individual countries but acts as a single Party to the Paris Agreement. There is a complex interplay between EU climate policy and member states' domestic climate policies. The EU sets Europe-wide targets for greenhouse gas emissions (GHG) backed by a set of binding regulations. Member states are allocated individual targets under an effort-sharing mechanism. Member states might exceed EU targets through their own climate policies. As a result, EU-mandated targets effectively act as a floor for GHG emission targets. This study treats each country, or EU member, the European Commission and the European Parliament as actors. Future studies may take a more complex approach, considering the influence of non-state and sub-national actors in shaping EU climate policy.

\section{EU climate policy}

The EU was the first Party to submit its intended nationally determined contribution (INDC) under the Paris Agreement, in March 2015. It included a legally binding target to reduce domestic GHG emissions by at least $40 \%$ by 2030 compared to 1990 levels. The INDC was converted into the EU's first NDC in October 2016 when the EU ratified the Paris Agreement. This commitment feeds into the wider spectrum of EU climate policy. Over the past decade, the EU has taken a progressively more ambitious approach to the challenges posed by climate change and the need to decarbonize its economy in order to limit GHG emissions.

In 2010, the European Commission published its strategy for smart, sustainable and inclusive growth which included a $20 \%$ reduction in GHG emissions by 2020 compared to 1990 levels; a pledge for $20 \%$ of total energy consumption to come from renewable energy; and a $20 \%$ increase in energy efficiency (the 'three times twenty' package). In 2011, the Commission published its long-term strategy or "roadmap for moving to a competitive low carbon economy in 2050," outlining a set of more ambitious targets for possible action for an 80\%-95\% emissions reduction by 2050. Later, in 2014, EU leaders met in the European Council and adopted a Commission proposal for a policy framework for climate and energy from 2020 to 2030 . The 2030 package set more ambitious targets of at least a $40 \%$ reduction in domestic GHG emissions 
(the NDC target); at least $27 \%$ of total energy consumption generated from renewable energy; and at least a $27 \%$ increase in energy efficiency.

The instruments employed for achieving these targets are the EU Emissions Trading System (ETS), established in 2005; the Renewable Energy Directive, establishing individual national renewable energy targets; and the Energy Efficiency Directive, with a set of national targets and the imposition of binding targets to lower carbon dioxide $\left(\mathrm{CO}_{2}\right)$ emissions for cars and vans. Following the Paris Agreement, it became clear that more ambitious targets would need to be set for 2050, giving added importance to the MCS. In March 2018, European leaders in the European Council directed the Commission to produce a new long-term climate strategy by the first quarter of 2019. In November 2018, the European Commission published a communication entitled "A Clean Planet for all - A European strategic longterm vision for a prosperous, modern, competitive and climate neutral economy." Instead of focusing on GHG emission reduction targets as the primary climate policy tool, this document called for netzero emissions by 2050. It outlines eight scenarios that offer policy pathways for EU member states. Six of the scenarios fail to achieve net-zero emissions, but two explore ways of achieving carbon neutrality by 2050 and negative emissions thereafter using carbon sinks. The communication outlines a set of key strategic policy building blocks including energy efficiency, maximizing renewables, clean mobility, a circular economy, a smart network infrastructure, the creation of carbon sinks, and the use of carbon capture and storage.

In recent years, the EU's climate policy has had a noticeable impact on GHG emissions. EU emissions continue to decline from 1990 levels, as shown in Figure 1. Germany, the United Kingdom (U.K.), France, Italy, Poland and Spain account for almost two-thirds of the EU's total emissions, as shown in Figure 2.

Figure 1. EU member states' total GHG emissions, 1990-2016 (excluding land use, land-use change, forestry (LULUCF) and indirect emissions).

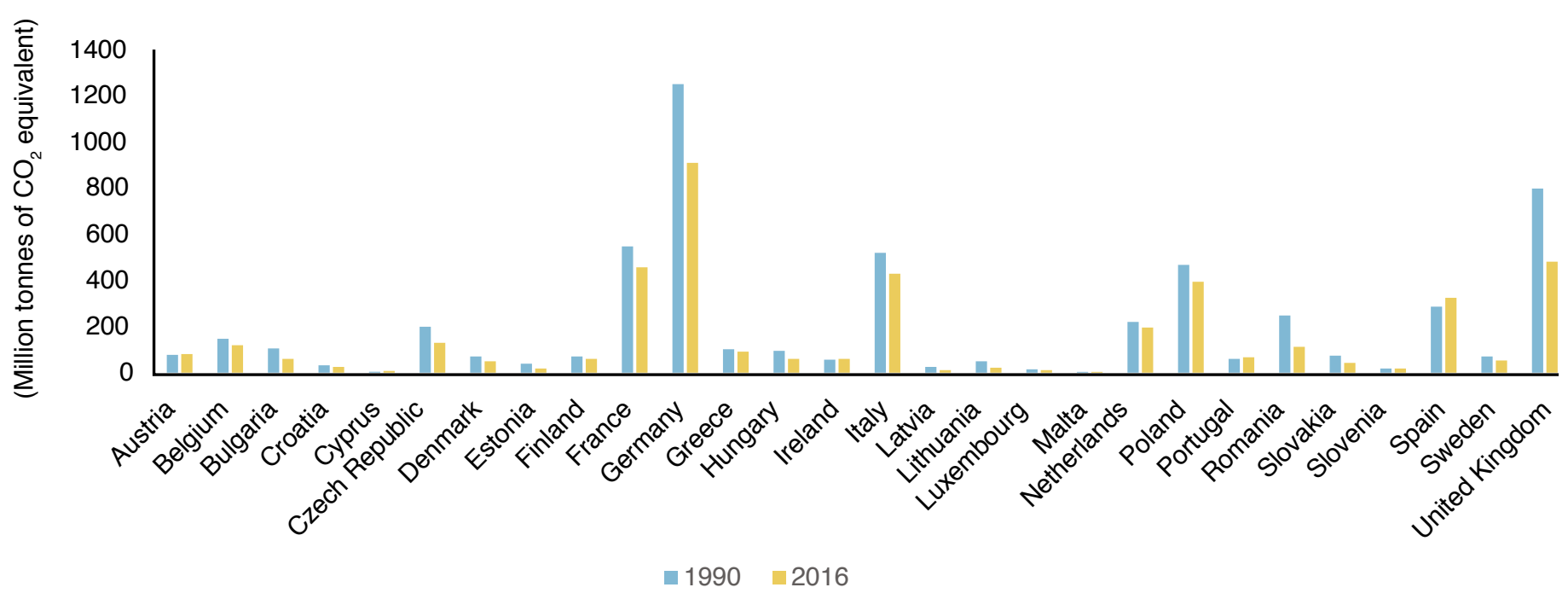

Source: European Environment Agency. 
Figure 2. EU member states' share of total GHG emissions (\%).

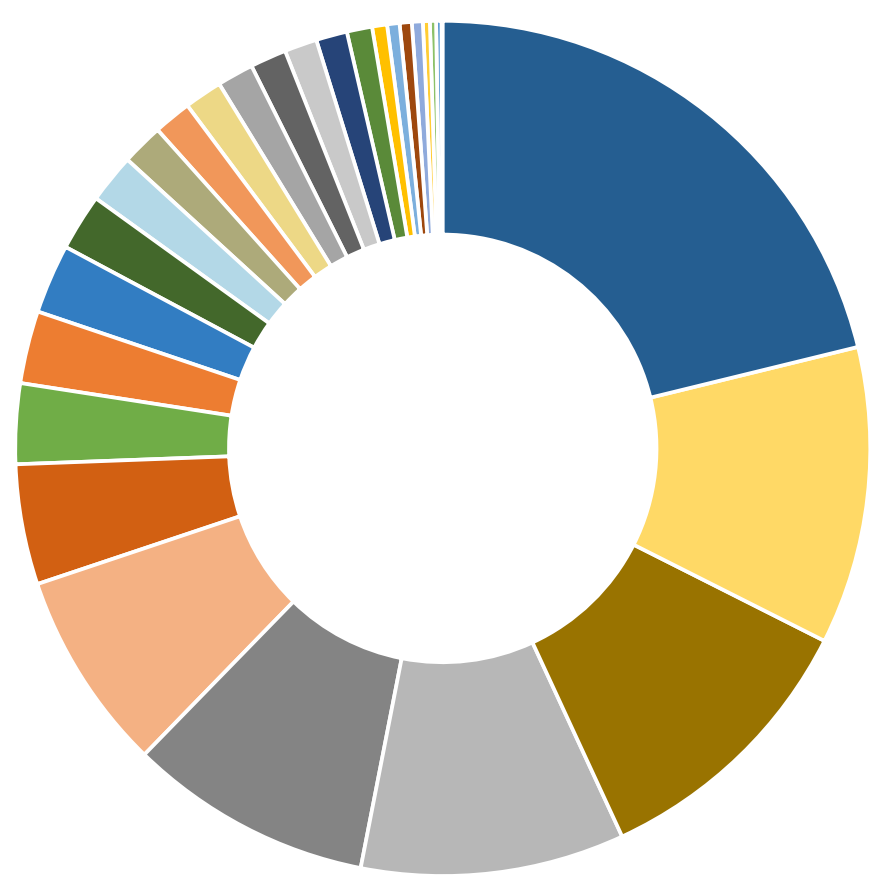

\begin{tabular}{lllll}
\hline Austria & Belgium & Bulgaria & Croatia & Cyprus \\
Czech Republic & Denmark & Estonia & Finland & France \\
Germany & Greece & Hungary & Ireland & Italy \\
Latvia & Lithuania & Luxembourg & Malta & Netherlands \\
Poland & Portugal & Romania & Slovakia & Slovenia \\
Spain & Sweden & United Kingdom &
\end{tabular}

Source: European Environment Agency.

\section{EU member states' national climate policies}

EU member states were due to submit their draft national climate and action plans by the end of 2018 to feed into the EU 2030 climate and energy targets. A growing number of regions, municipalities and business associations in the EU are also drafting their own plans for 2050. There is a wide spectrum of national policies related to climate change, particularly around setting targets for $\mathrm{CO}_{2}$ reductions and other GHG emissions. Only two EU members - the U.K. and Sweden - have enshrined their emission targets in law. Other countries have a wide range of policies and strategies with varying degrees of commitment to limiting such emissions. Many EU countries are constrained by their national energy systems. Germany, for example, undertook a shutdown of its nuclear power reactors in the aftermath of the 2011 Fukushima nuclear disaster in Japan while sharply increasing its renewable power generation capacity. However, in the absence of mechanisms to manage the price differential between coal and natural gas, Germany witnessed wholesale switching from gas-fired 
power plants to coal-fired generation, increasing its GHG emissions. Poland and other Eastern European countries continue to depend on coal for a significant proportion of their generating capacity and are unwilling to switch from this domestic resource to imported fuels. Other countries are in an enviable position in relation to legacy energy systems. For example, Portugal generates a third of its energy from hydropower while also enjoying high solar irradiance that makes it particularly suitable for solar power.

Furthermore, not all EU governments face the same level of domestic political pressure to reduce carbon emissions. Typically, electorates in Northern European countries show higher levels of concern over reducing national GHG emissions than those elsewhere. The political composition of EU member state governments also factors into national emissions targets. Typically, but not always, left-leaning governments tend to be tougher on emissions targets than right-leaning governments. When drafting EU climate policies and setting emissions reduction targets, member states typically form into coalitions that have subregional and political elements. Nordic states typically join a 'progressive' coalition that includes the U.K. and the Netherlands, while Poland leads a coalition of countries in Eastern Europe, known as the Visegrád Group, that depend heavily on coal for power generation. The Visegrád Group members are concerned about the economic damage to their domestic coal industries and are unwilling to become dependent on imported Russian gas.

\section{EU governance process}

Decision-making in the EU involves a set of complex interactions between three main institutions: the European Commission, the Council of the European Union and the European Parliament. The European Commission is the EU's executive arm that submits proposals for new legislation to the European Parliament and Council. The European Council, known informally as the EU Council, consists of the heads of state or government of the member states, together with its President and the President of the Commission and meets to adopt laws and coordinate policies. It defines the EU's general political direction and priorities. The EU Council is the key body that ultimately decides EU policy and legislation and is separate from the European Council. The European Parliament is the EU'S directly elected parliamentary institution. Although it cannot initiate new legislation, it plays a key role in the legislative function of the EU together with the Council of the European Union and the European Commission.

While the European Parliament can force through amendments to legislative proposals and has a veto, it is in the Council of the European Union that EU laws - known as directives - are made or broken. The model of CDMPs used in this paper is intended to focus on the interactions between actors that represent country-level interests within the EU Council. 


\section{KTAB and the Spatial Model of Politics (SMP)}

he KAPSARC Toolkit for Behavioral Analysis (KTAB) is a platform that enables CDMPs to be modeled and analyzed. CDMPs capture the political bargaining process, both explicit and implicit, among a set of actors, which can include individuals, institutions, constituencies and identifiable groups or 'blocs'.

This paper presents an analysis of plausible outcomes for CDMPs, based on the spatial model of politics (SMP), one of the most prominent and most established CDMP models. The SMP simulates how actors interact with and influence one another to arrive at a 'feasible outcome' for the modeled question. This paper gives a model-based view of the expected outcome for actors' collective support for - or opposition to - enhancing the EU's emissions target under the MCS. The aggregated knowledge of the experts gives a representation of the current political landscape (referred to as turn 0), but all simulations beyond turn 0 are based purely on the KTAB SMP calculations.
This paper focuses on the logic of the analysis and describes the results. It does not contain a detailed technical description of the underlying model and its calculations. Interested readers are pointed to two related KAPSARC papers for more detail:
"An Introduction to the KAPSARC Toolkit for Behavioral Analysis (KTAB) Using One- Dimensional Spatial Models" (Wise, Lester and Efird 2015a); and
"Multidimensional Bargaining Using KTAB" (Wise, Lester and Efird 2015b).

Both papers are freely available from KAPSARC's website and the KTAB portal, as is the program's source code and documentation. Please visit http:// www.ktab.software for all related papers, the latest version of the software and all materials of interest related to KTAB. By separating the technical detail from this applied discussion, the authors hope to make the discussion of what will be a relatively new field to most readers more accessible. 


\section{Analyzing the Political Feasibility of Enhancing the EU's MCS}

$\mathrm{T}$

The first stage of a KTAB analysis is to define the question, i.e., defining the topic in contention with the various actors or stakeholders. This study specifically aimed to determine the political feasibility of reaching an agreement on the Commission's original 2050 target before the publication of its net-zero strategy. It sought to answer the question in mid-2018: What are stakeholders' positions on the EU-wide 80\% 2050 emissions reduction target in the next framework package? Subject matter experts familiar with EU governance and political dynamics surrounding this issue were asked a series of questions regarding the qualities of the relevant actors and stakeholders with respect to the modeled question. Relevant stakeholders then advocated for a position on the linear scale defined in Figure 3.

\section{KTAB SMP data inputs}

The data for this study were collected in semistructured interviews with 11 subject matter experts in London and Brussels between February and April 2018.
Subject matter experts included the following:

Murray Birt, Vice President, DWS (formerly known as Deutsche Asset Management)

Anthony Froggatt, Senior Research Fellow, Chatham House

Jonathan Gaventa, Director, E3G Brussels Office

Pete Harrison, Transport Program Director, European Climate Foundation

Erica Hope, Senior Associate, European Climate Foundation

Francois-Regis Mouton, EU Affairs Director, International Association of Oil and Gas Producers

Carlos Ochoa, Senior Director, Strategic Communications, FTI Consulting

Figure 3. Spectrum of stakeholders' positions on EU-wide $80 \% 2050$ emissions reduction target.

What are stakeholders positions on the EU-wide $80 \% 2050$ emissions reduction target in the next framework package?

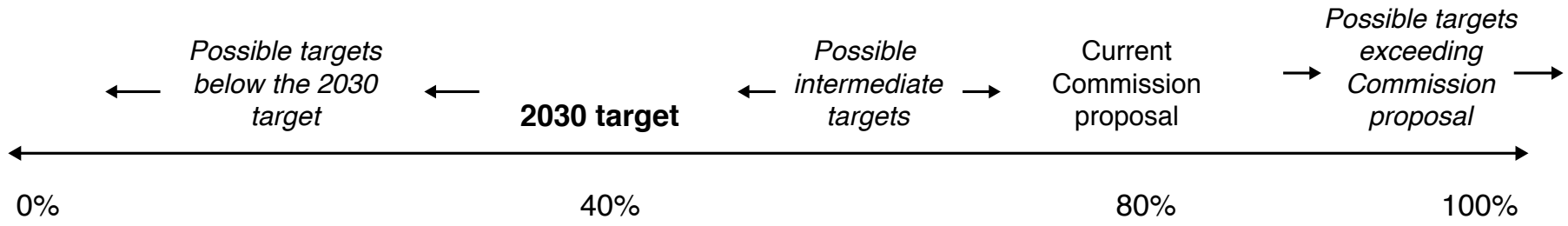

Source: KAPSARC. 
Kamila Piotrowska, EU Affairs Manager, International Association of Oil and Gas Producers

Nareg Terzian, Media and EU Affairs Manager, International Association of Oil and Gas Producers

Shane Tomlinson, Director, E3G London Office

Dr. Coby van der Linde, Director, Clingendael International Energy Programme.

We identified the key actors involved in the decisionmaking process for our specific question. The list of actors included the $28 \mathrm{EU}$ member states, the European Commission and the European Parliament. We then asked experts to assign each actor three numeric values for the following properties:

Position: the location of an actor on the linear spectrum shown in Figure 3. In other words, what is the actors' advocacy concerning supporting or opposing a more ambitious emissions reduction target in the next framework package?

Influence: the relative degree of political power for each actor. The most powerful actor is assigned a value of 100 and others are weighted relative to the most powerful actor.

Salience: the relative priority each actor assigns to the new emissions reduction target compared with other issues over which it must exert influence.

After the data collection process, experts' data are aggregated into one dataset, which we refer to as the baseline dataset, a weighted average of values assigned by experts for each of the three values needed for a KTAB simulation. Table 1 shows the baseline dataset.

\section{KTAB SMP simulation results}

This paper presents the KTAB results in the form of bar graphs and line graphs. The bar graphs show the distribution of actors' positions, influence and salience at different points in the simulation. The line graphs show how positions for each actor change over the course of the simulation.

The KTAB simulation captures the dynamic of time through a series of 'turns.' While not a precise, real-world measurement, each subsequent turn reflects a step interval iteration in the CDMP. The simulation continues over a series of turns until the expected change in positions for the next turn falls below a small percentage threshold. In other words, the simulation ends when actor positions are no longer appreciably changing, reaching a kind of steady state. The end of the simulation need not result in agreement or disagreement; it simply reflects that the KTAB model has calculated that little more will change in future turns. This particular simulation ran for 15 turns, which is a typical duration for an issue such as the one under consideration.

Figure 4 shows the distribution of actors' positions and effective power for the baseline data set (before any simulation), referred to as 'turn 0' of the simulation. The bars represent actors, the location on the horizontal axis presents their positions on the question of the EU's 2050 target, and the height of each bar reflects their exercised power, calculated by multiplying their influence multiplied by their salience.

Figure 4 shows that the vast majority of actors are either in favor of the current Commission proposal or slightly opposed/slightly in favor of a more ambitious proposal. Six countries support a much less ambitious 2050 target, including the four 
Table 1. Baseline dataset - weighted average of expert inputs.

\begin{tabular}{|c|c|c|c|c|}
\hline Actor & Abbreviation & Influence & Position & Salience \\
\hline Austria & A & 53.8 & 80 & 57 \\
\hline Belgium & B & 53.3 & 80 & 55 \\
\hline Bulgaria & $B G$ & 51.7 & 60 & 41.3 \\
\hline Croatia & $\mathrm{HR}$ & 51.7 & 70 & 40 \\
\hline Cyprus & $\mathrm{CY}$ & 10 & 80 & 60 \\
\hline Czech Republic & $\mathrm{CZ}$ & 68.8 & 55 & 45 \\
\hline Denmark & DK & 63.8 & 90 & 74.4 \\
\hline Estonia & EST & 36.7 & 80 & 46.3 \\
\hline Finland & FIN & 60 & 80 & 62 \\
\hline France & $\mathrm{F}$ & 88.8 & 80 & 79 \\
\hline Germany & D & 90 & 85 & 80 \\
\hline Greece & GR & 27.5 & 75 & 35 \\
\hline Hungary & $\mathrm{H}$ & 57.5 & 50 & 42.5 \\
\hline Ireland & IRL & 50 & 85 & 51 \\
\hline Italy & 1 & 65.6 & 80 & 47 \\
\hline Latvia & LV & 30 & 80 & 32.5 \\
\hline Lithuania & LT & 43.3 & 70 & 32.5 \\
\hline Luxembourg & $\mathrm{L}$ & 31.3 & 80 & 40 \\
\hline Malta & M & 8.3 & 80 & 48.8 \\
\hline Netherlands & $\mathrm{NL}$ & 70 & 80 & 73.6 \\
\hline Poland & $\mathrm{PL}$ & 81.3 & 45 & 80 \\
\hline Portugal & $\mathrm{P}$ & 35 & 80 & 48.8 \\
\hline Romania & RO & 60 & 60 & 37.5 \\
\hline Slovakia & SK & 48.3 & 60 & 55.6 \\
\hline Slovenia & SLO & 63.3 & 75 & 55.6 \\
\hline Spain & $\mathrm{E}$ & 65 & 80 & 53 \\
\hline Sweden & S & 72.5 & 90 & 75.6 \\
\hline United Kingdom & GB & 87.5 & 85 & 70.6 \\
\hline EU Commission & COM & 82.5 & 80 & 73 \\
\hline EU Parliament & PAR & 75 & 85 & 69 \\
\hline
\end{tabular}

Source: KAPSARC expert interviews.

members of the Visegrád Group (Poland, Hungary, is currently strong support for a 2050 target of an the Czech Republic and Slovakia), plus Romania and Bulgaria. Thus, the expert data indicate there $80 \%$ reduction in GHG emissions but that there are still some detractors. 
Figure 4. Initial (turn 0) actor distribution of actor positions and effective power.

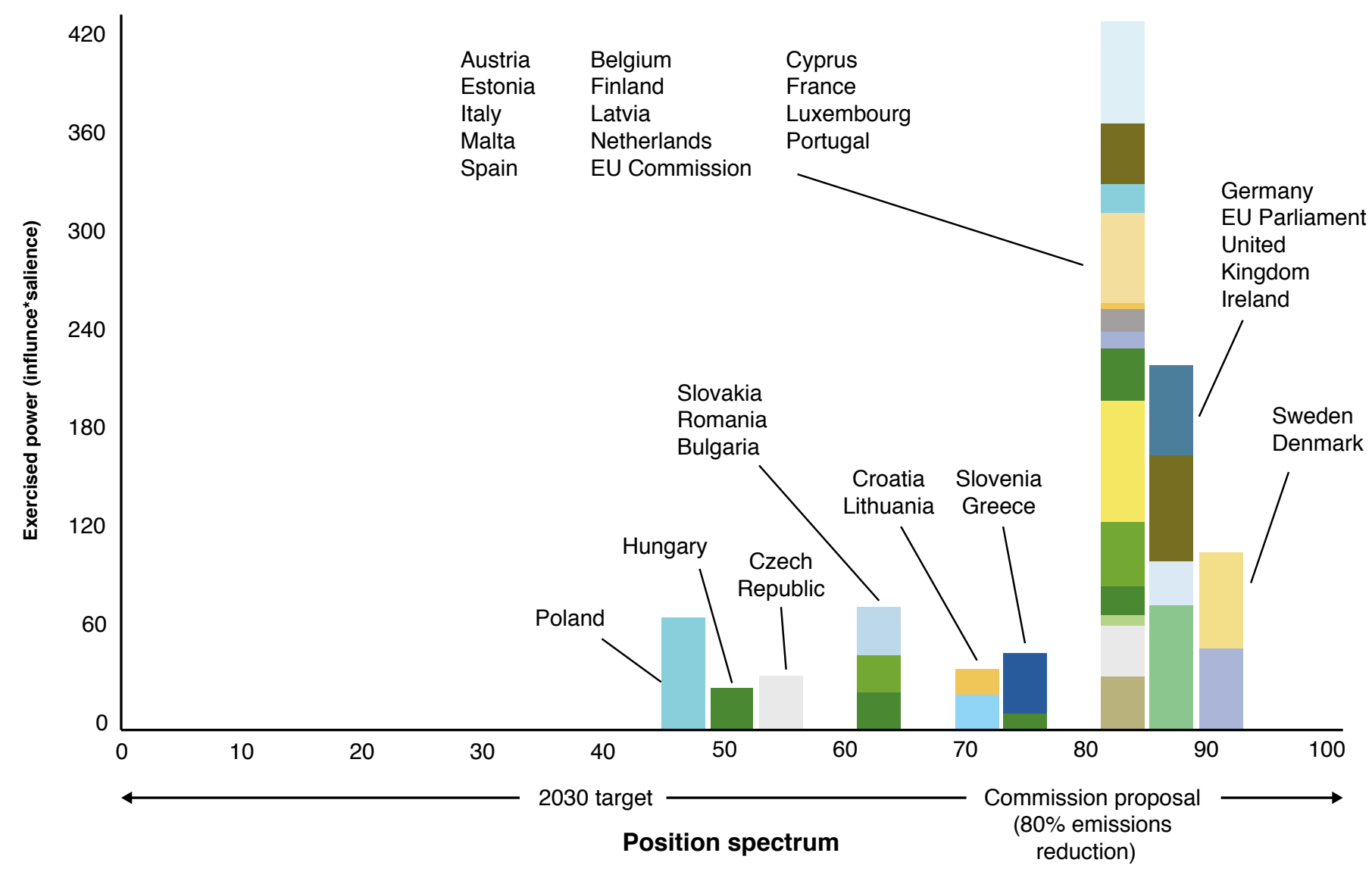

Source: KTAB simulation.

\section{EU member states' appetite for increasing emissions reduction targets}

Figure 5 displays turn 15, the last turn of the simulation, reflecting the actors' final positions after all KTAB calculations. This can be interpreted as a politically-feasible outcome: the model calculated what is most likely after a CDMP among actors around the question of the EU 2050 emissions reduction target. Figure 5 indicates that while a consensus forms, it is not around the $80 \%$ reduction in emissions proposed by the Commission, even though the majority of experts interviewed thought this was the most likely outcome. Instead, the KTAB simulation indicates that a politically feasible consensus is likely to emerge at a lower emissions reduction target of approximately $70 \%$, 10 percentage points less than the hypothetical Commission target. The behavior of several actors during the simulation was notable, particularly the EU Commission, Poland and Sweden. These actors were the only detractors to the consensus that emerged at the end of the simulation. Poland and Sweden remained at their initial positions, with the EU Commission ultimately shifting toward a target of $60 \%$ from its initial position of $80 \%$. The behavior of the Commission reflected by the model may seem counterintuitive, but it can be interpreted as an effort by the Commission to build a consensus in the face of opposition to the higher reduction target. The intermediate position of the Commission indicated its efforts to bring Poland on board and to search for 
a lower target that would still be acceptable to more progressive member states.

Figure 6 displays the turn-by-turn change in the position of actors during the simulation negotiating rounds, or how the KTAB simulation calculates that each actor's position changes over time. Poland and Sweden have oppositional preferred outcomes and neither was willing to compromise on their original positions. This calculated result is driven in part by their relatively high exercised power: the combination of influence and salience (or commitment). Conversely, the remaining members of the Visegrád Group - Hungary, the Czech Republic and Slovakia - and the other initial outliers joined the consensus over the course of the simulation. The first countries to converge were Romania and Hungary. Romania finds the advocacy of Ireland to be compelling on this issue and eventually joins the consensus a few turns later. Meanwhile, Hungary responded to the advocacy of the European Parliament during the first turn to immediately join the forming consensus.

Figure 5. Final (turn 15) distribution of actor positions and effective power.

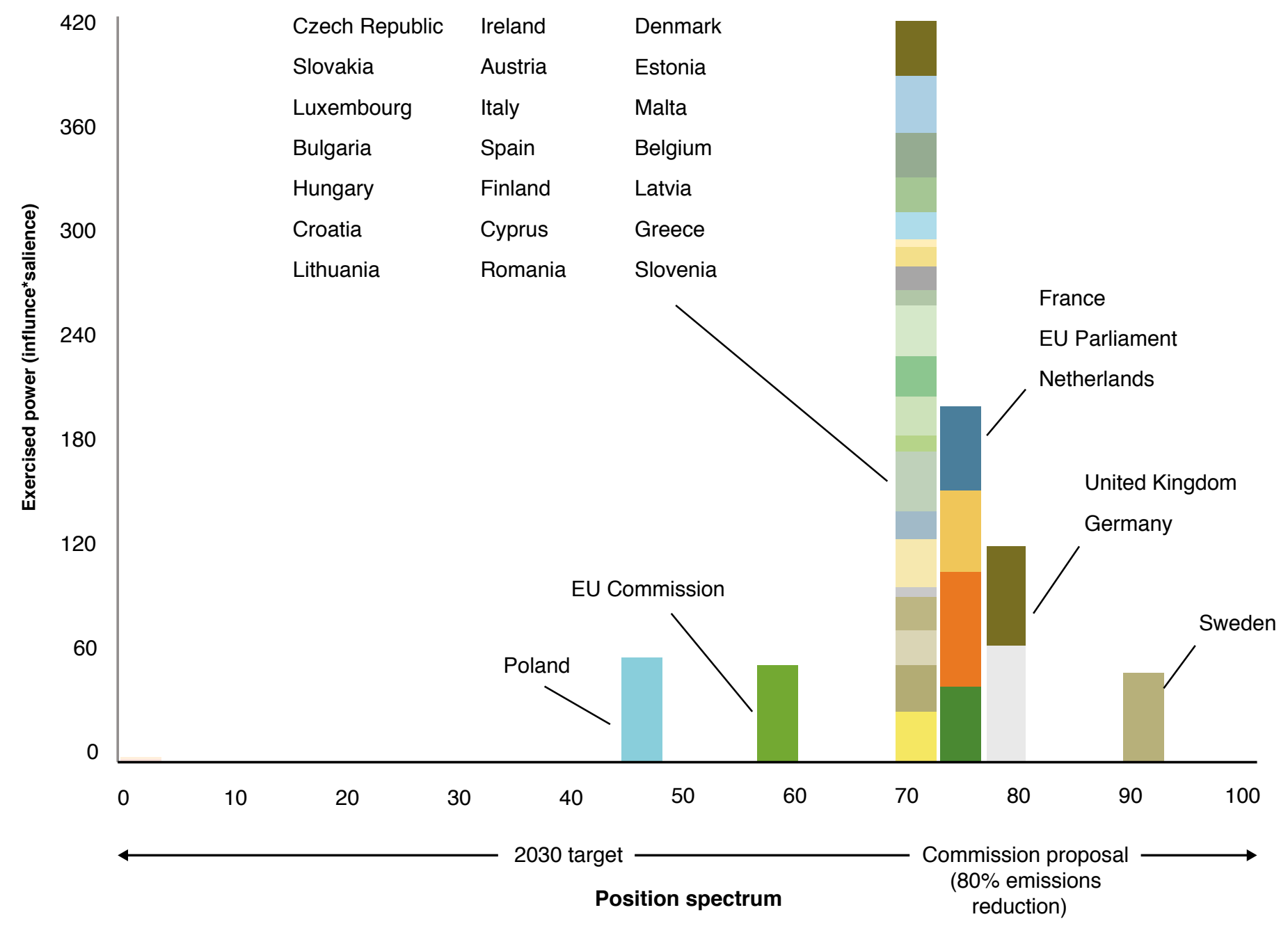

Source: KTAB simulation. 
Figure 6: Changing actor positions by turn (all actors).

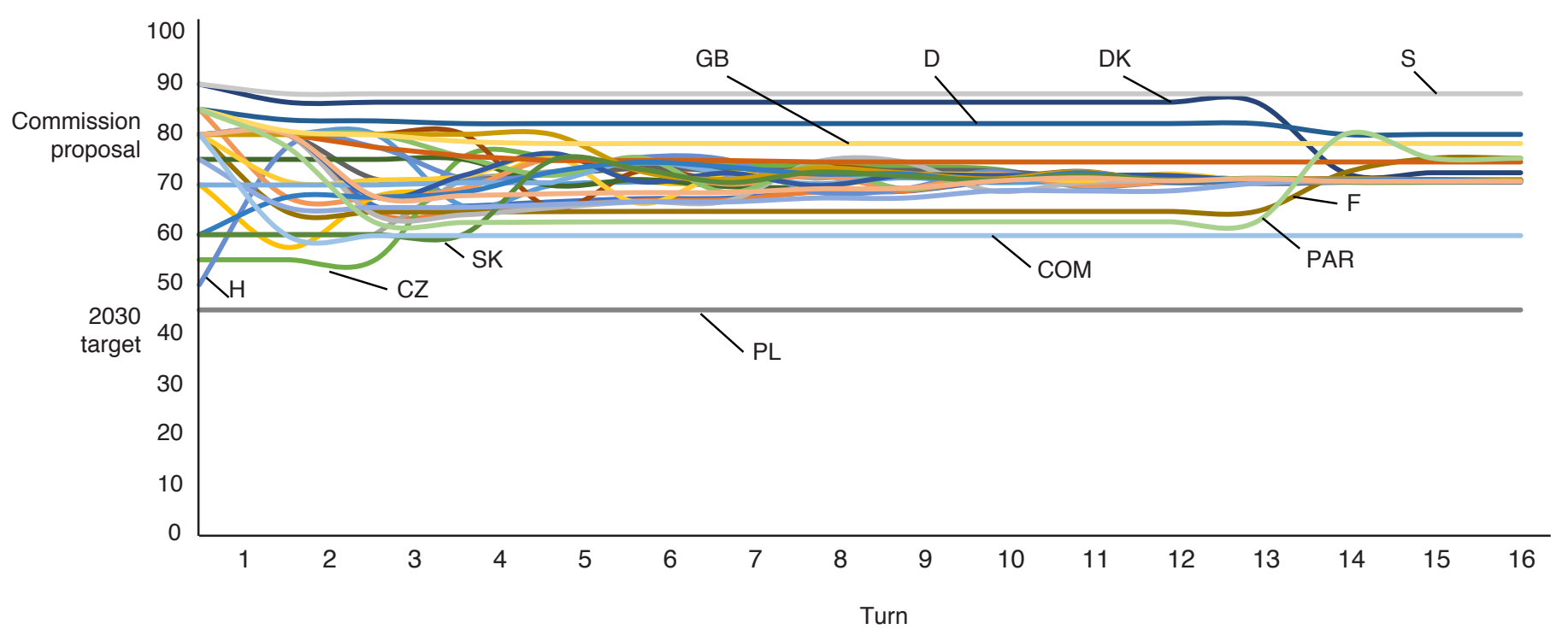

Source: KTAB simulation.

Hungary's concession causes Bulgaria and the Czech Republic to join the consensus. Once these actors have all agreed to roughly the same outcome, the final outlier, Slovakia, then shifts its position toward the consensus.

The EU Commission played an interesting role in the simulation, significantly shifting its position toward a lower reduction target in the first turn to build consensus among the most negative detractors, with a particular, initial focus on Hungary. The Commission then remained at its lower position for the rest of the simulation. This can be interpreted as an attempt to break up the Visegrád group's resistance to the higher reduction target supported by the majority of EU member states. The Commission's continued advocacy at this new lower position may be viewed as a signal that it thought an outcome supported by all actors was crucial.

Figure 7 focuses just on the Visegrád group actors (though based on the same simulation with all actors), given their critical role in the simulated negotiations. Figure 7 shows the changing positions of Poland, Hungary, the Czech Republic and Slovakia. Most notably, Poland stuck to its initial position during the entire simulation, remaining the only actor in the group unwilling to concede any ground. Hungary was the first to join a $70 \%$ reduction target consensus, followed by the Czech Republic in the second turn and finally Slovakia in the third turn. The advocacy of the European Parliament and the Netherlands was an important factor in obtaining these concessions.

\section{Brexit scenario}

To evaluate the effect of the U.K.'s proposed withdrawal from the EU, we reran the simulation removing the U.K. as an actor to arrive at a Brexit scenario. Initial actor positions and other data remained unchanged, meaning that the distribution of initial actor positions and effective power is 
Figure 7: Changing actor positions by turn (Visegrád group).

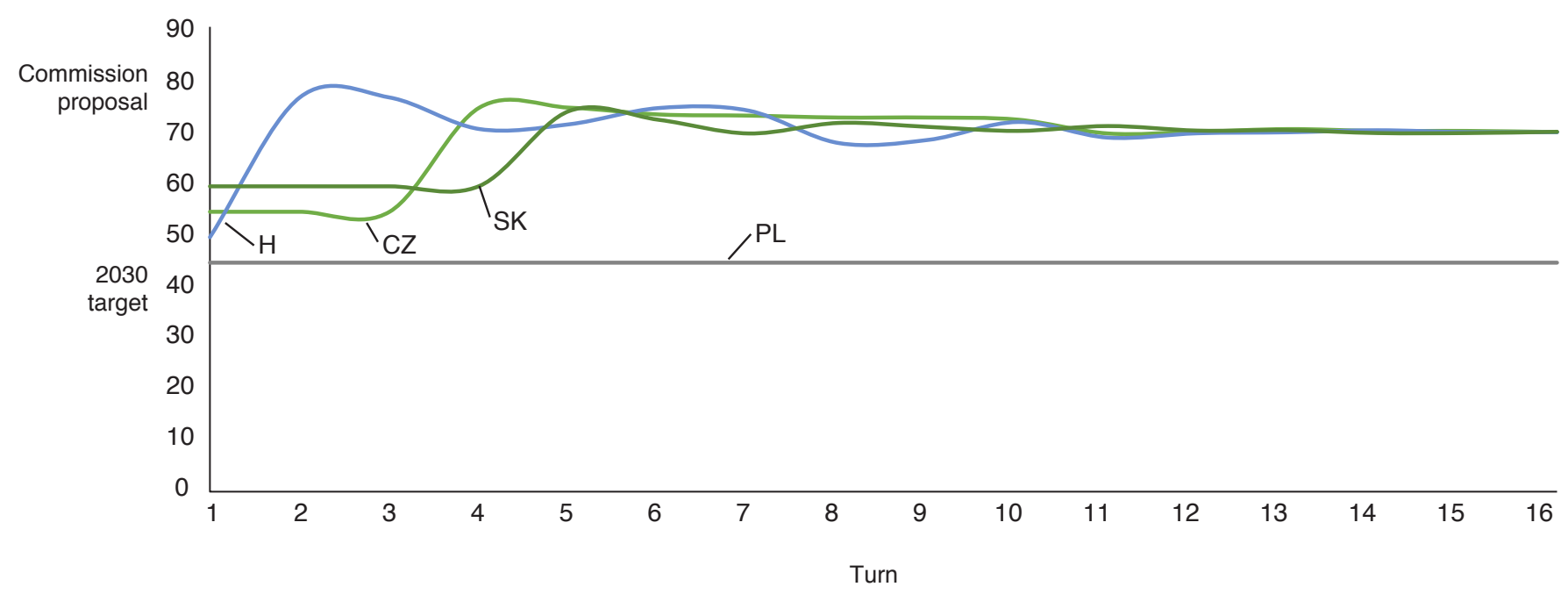

Source: KTAB simulation.

identical to that displayed in Figure 5, except with the removal of the UK as an actor. As in the baseline simulation, the Brexit scenario ran for 15 turns. Figure 8 displays the results of the simulation. The positions of the majority of the outliers at the conclusion of the Brexit scenario simulation Poland, the EU Commission and Sweden - were largely unchanged from the initial simulation, with the final $70 \%$ consensus also relatively unchanged. These simulation results indicate that any 'Brexit effect' on this aspect of climate discussions within the EU climate governance framework is unlikely. However, upon closer observation of the interaction between the actors reveals some subtle differences between the two simulations.

The Visegrád group, along with Romania and Slovakia, which all initially advocated for a lower emissions target, behaved quite similarly to the baseline simulation, as Figure 9 shows. The Polish position remained firmly in support of a much lower target for the duration of the simulation, while the other members ultimately joined the consensus position. Again Hungary was the first to peel away from the Visegrád cluster. Subsequently, Hungary was joined by Romania, then the Czech Republic and finally Slovakia. In this scenario, the advocacy of Finland and Germany were important drivers for these concessions, suggesting an emerging Finnish presence in the debate following Brexit.

The simulated behavior of the EU Commission was unchanged from the baseline simulation, as it again unsuccessfully attempted to foster a compromise position by remaining at a central point between the $70 \%$ consensus and Poland for most of the simulation. Similar to Poland, Sweden again remained at its position before the simulation. However, in the Brexit scenario, Sweden was joined by Denmark, which also remained in favor of a more aggressive 2050 target.

The main takeaway from the Brexit scenario was the emergence of some actors, such as Finland 
Figure 8. Final (turn 15) distribution of actor positions and effective power - Brexit scenario.

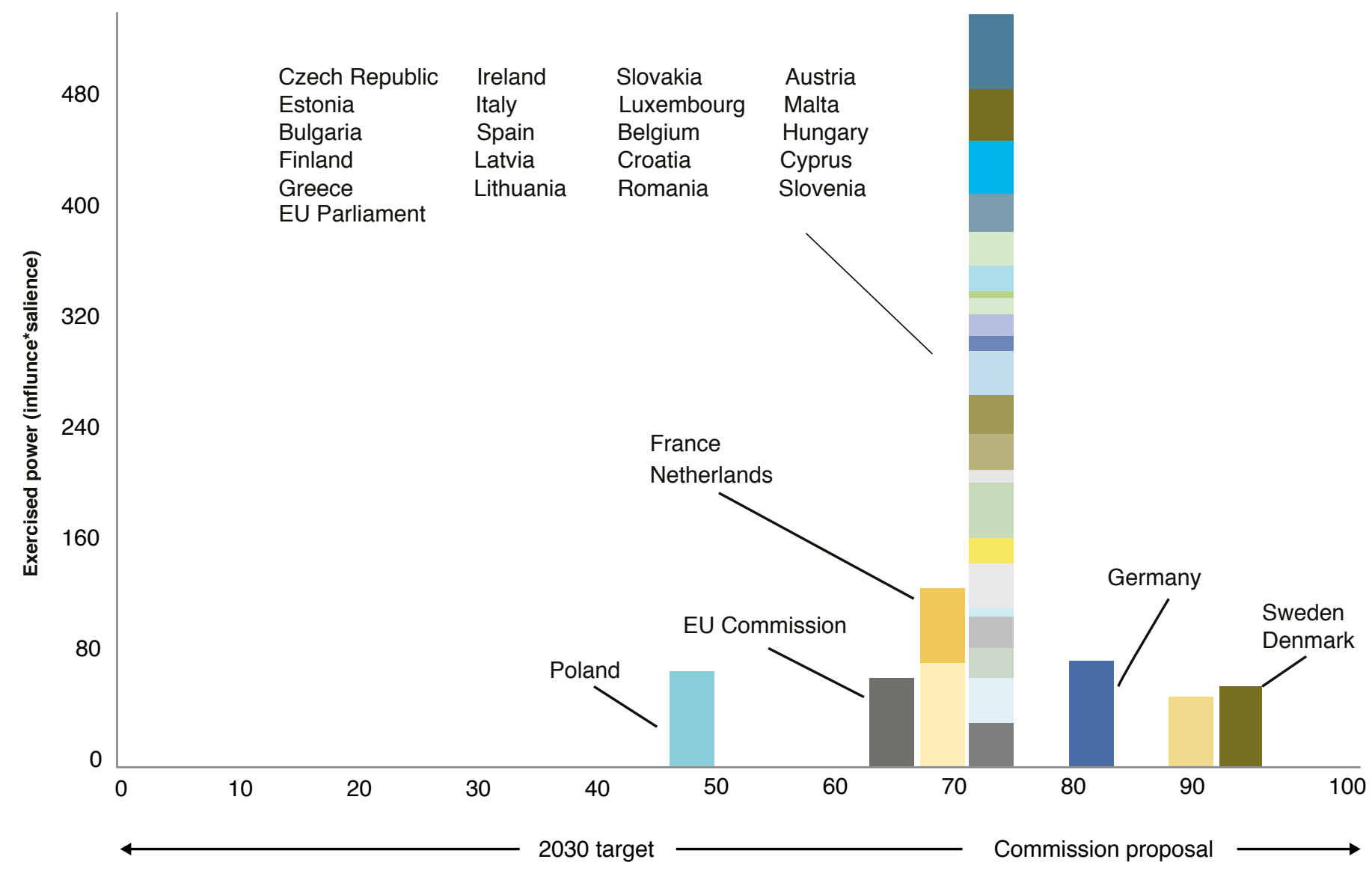

Position spectrum

Source: KTAB simulation.

and Germany, playing a larger role than before as leaders of the discussion. The Netherlands and France remained active in both simulations, although slightly less so in the Brexit scenario. This outcome contrasts with the consensus view of the experts interviewed who saw France, the
Netherlands and Sweden assuming the leadership role left open following Brexit. In general, however, the Brexit scenario does not show a major difference to the previous simulation in the politically feasible outcome, only in the interactions among the actors to form a consensus. 
Figure 9. Changing actor positions by turn - Brexit scenario (all actors).

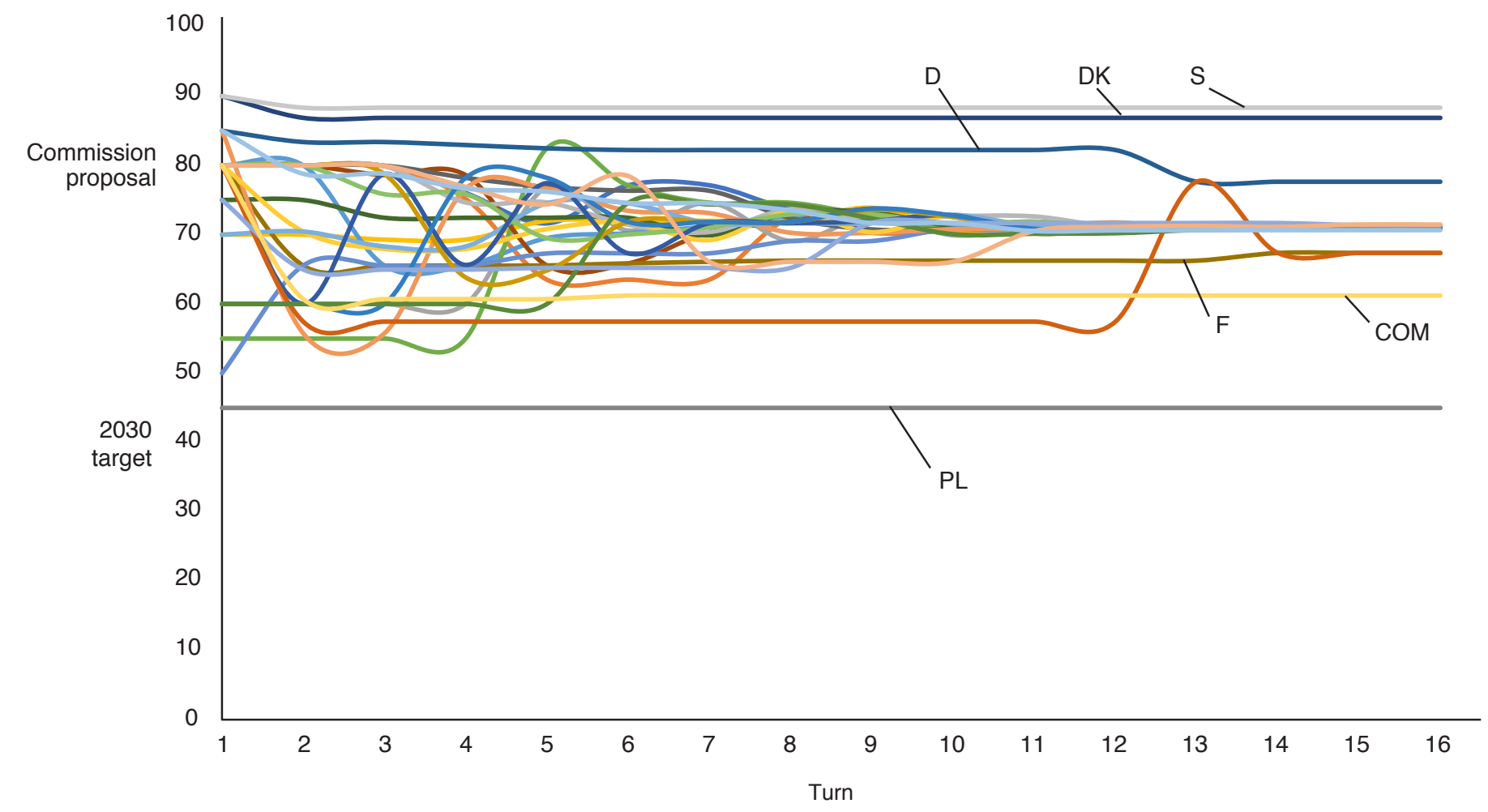

Source: KTAB simulation. 


\section{Conclusions}

$\mathrm{T}$ The disparities between EU climate policies and individual member states' climate policies virtually guaranteed that reaching an EU-wide agreement on a mid-century climate policy would be an arduous journey, both in selecting the reduction target as well as approving the mechanisms used to achieve the target. The KTAB simulations provide insights on the complexity of the direction of EU member states' climate policy, especially among states with high political salience either in support of, or resistant to, an ambitious GHG reduction target. Indeed, the KTAB simulations identified both outliers to a final consensus (Poland and Sweden), as well as the political unfeasibility of $80 \%$ as an agreed reduction target. This simulated outcome stands in contrast to the views of many of the subject matter experts interviewed, who argued that the Commission's anticipated $80 \%$ target would not only be achieved but could potentially be surpassed.

The KTAB simulations suggested that the most significant obstacle to achieving an EU-wide agreement was likely to be Poland's unwillingness to shift its position and entertain any counter proposals. Many of the experts interviewed for this study highlighted Poland's historically intransigent position regarding changes to climate policies, and the simulation reflected this behavior. This suggests that some concessions will likely be needed to persuade Polish decision-makers to accept a higher reduction target. The change of tack in the European Commission's November 2018 "Communication" suggests that it recognizes the requirement for a more holistic approach, based on a wide range of policy instruments to achieve a net-zero result, rather than simply setting carbon emissions reduction targets.

Interestingly, many of the experts interviewed for this study downplayed the effect that they thought Brexit would have on climate policy debates, despite Britain's historical role as a leader in EU climate policies. The KTAB simulations confirmed this consensus, with the results generally unaffected by removing the U.K. as an actor. 


\section{References}

European Commission. 2010. "Europe 2020: A Strategy for Smart, Sustainable and Inclusive Growth." Communication from the Commission. http://eur-lex.europa.eu/LexUriServ/LexUriServ. do?uri=COM:2010:2020:FIN:EN:PDF

European Commission. 2011. "A Roadmap for Moving to a Competitive Low Carbon Economy in 2050." Communication from the Commission to the European Parliament, the Council, the European Economic and Social Committee and the Committee of the Regions. https://eur-lex.europa.eu/legal-content/EN/ TXT/?uri=CELEX:52011DC0112

European Commission. 2014. "A Policy Framework for Climate and Energy in the Period from 2020 to 2030." Communication from the Commission to the European Parliament, the Council, the European Economic and Social Committee and the Committee of the Regions. http://register.consilium.europa.eu/doc/ srv?l=EN\&f=ST\%205644\%202014\%20REV\%201

European Commission. 2018. "2050 Long-Term Strategy." https://ec.europa.eu/clima/policies/strategies/2050_en

European Environment Agency. 2018. "EEA

Greenhouse Gas data viewer." https://www.eea. europa.eu/data-and-maps/data/data-viewers/ greenhouse-gases-viewer
Mollet, Paul, Saleh Al Muhanna, and AlJawhara Al Quayid. 2018. "The Politics of European Union Climate Governance." KAPSARC Discussion Paper. October. KS--2018-DP44. DOI: 10.30573/KS--2018-DP44.

United Nations Environment Programme. 2018. "Emissions Gap Report." http://wedocs.unep. org/bitstream/handle/20.500.11822/26895/ EGR2018_FullReport_EN.pdf

United Nations Framework Convention on Climate Change (UNFCCC). 2015. "Intended Nationally Determined Contribution of the EU and its Member States." http://www4.unfccc.int/ndcregistry/ PublishedDocuments/European\%20Union\%20First/ LV-03-06-EU\%20INDC.pdf

United Nations Framework Convention on Climate Change (UNFCCC). 2015. "The Paris Agreement." https:// unfccc.int/sites/default/files/english_paris_agreement.pdf

Wise, Ben, Leo Lester and Brian Efird. 2015a. "An Introduction to the KAPSARC Toolkit for Behavioral Analysis (KTAB) Using One-Dimensional Spatial Models." KAPSARC Discussion Paper. May. DOI: KS-1517-DP011A.

Wise, Ben, Leo Lester and Brian Efird. 2015b."Multidimensional Bargaining Using KTAB." KAPSARC Discussion Paper. November. DOI: KS-1524-DP018A. 


\section{Notes}

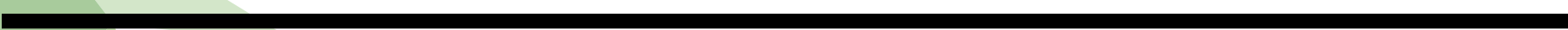




\section{About the Authors}

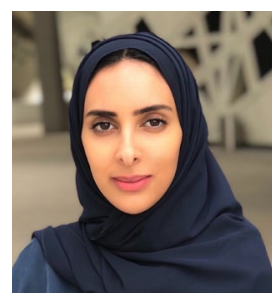

\section{Aljawhara AI Quayid}

Aljawhara is a senior research analyst in the Policy and Decision Science program with research interests in political economy, international affairs, finance and trade. She holds a B.Sc. in business administration, with a focus in finance, from Alfaisal University, Riyadh.

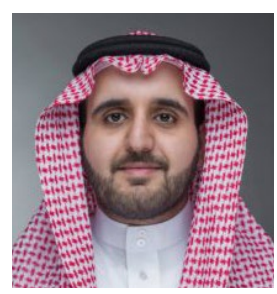

\section{Saleh AI Muhanna}

Saleh is a senior research analyst in the Policy and Decision Science program with interests in geopolitical research, international agreements and international trade. He holds a master's degree in international commerce and policy from George Mason University, Virginia, and a B.Sc. in economics from Pennsylvania State University.

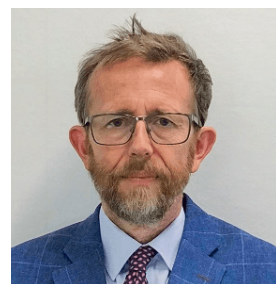

\section{Paul Mollet}

Paul is a research fellow in KAPSARC's Policy and Decision Sciences program. He is an analyst with over 25 years of experience covering international oil and energy markets. Paul has attended numerous OPEC meetings and written extensively about the oil industry in publications such as Platts Oilgram News, Argus Global Markets, and Petroleum Economist.

\section{About the Project}

This project evaluates the political feasibility for signatories of the Paris Agreement under the United Nations Framework Convention on Climate Change (UNFCCC) to effectively implement and iteratively improve their nationally determined contributions (NDCs), such that the rise of global temperature is limited to well below $2^{\circ} \mathrm{C}$ above pre-industrial levels. This includes five 'deep dive' studies for each of the world's top five emitters: China, the EU, India, Russia and the U.S.. Additionally, the project focuses on a global, geopolitical perspective for this question, based on non-expert data. 
INAPSARC

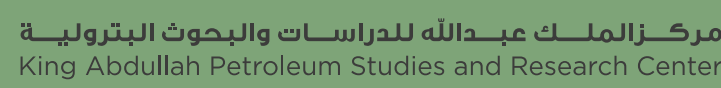

www.kapsarc.org 